\title{
Application of classification methods in fault detection and diagnosis of inverter fed induction machine drive: a trend towards reliability
}

\author{
C. Delpha ${ }^{2}$, D. Diallo ${ }^{1}$, M. El Hachemi Benbouzid ${ }^{3}$, and C. Marchand ${ }^{1}$ \\ 1 LGEP/Spee Labs, CNRS UMR 8507, Supélec, Université Paris Sud 11, Université Pierre et Marie Curie-Paris 6, France \\ 2 L2S, CNRS UMR 8506, Supélec, Université Paris Sud 11, Paris, France \\ 3 LBMS, IUT de Brest, Electrical Engineering Department, University of Western Brittany, Rue de Kergoat, BP 93169, \\ 29231 Brest Cedex 3, France
}

Received: 12 September 2008

Published online: 21 October 2008 - (c) EDP Sciences

Eur. Phys. J. Appl. Phys. 43, 245-251 (2008)

The Figure 5 have been misprinted, we sincerely apologise to the authors.

It should be replaced by:

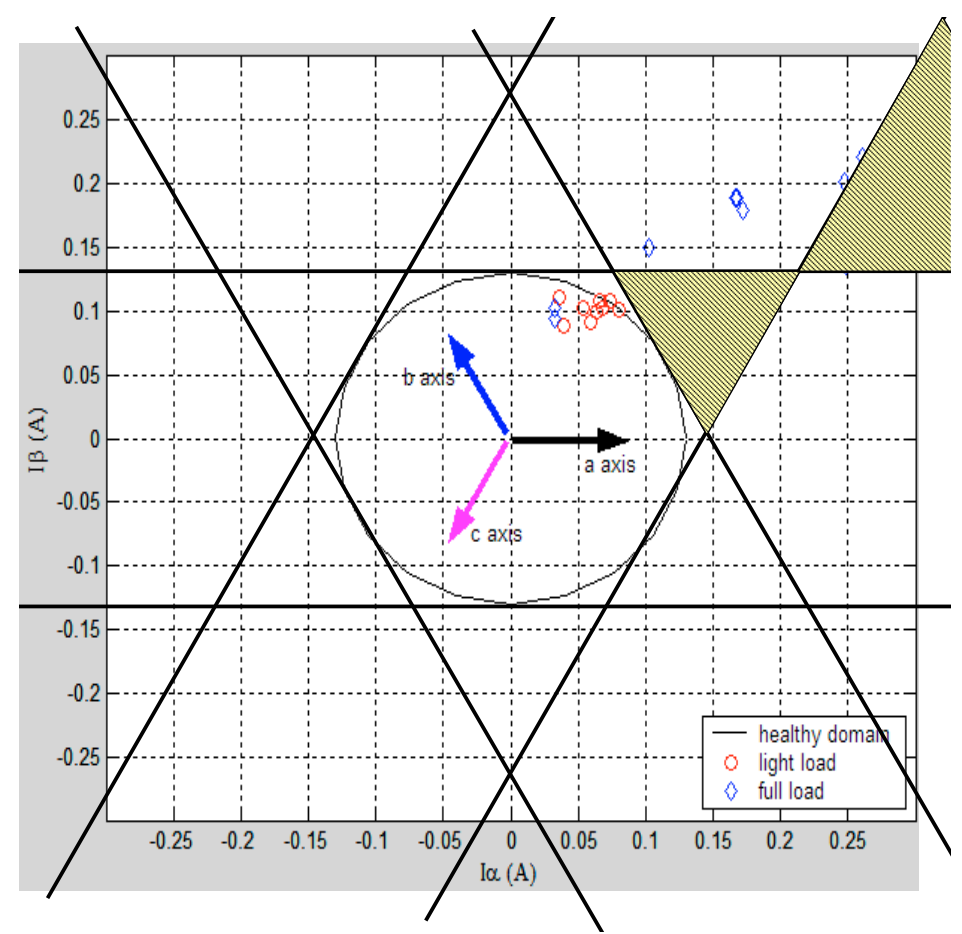

Fig. 5. Concordia mean current vector patterns. 